\title{
Effect of Temperature on L-Lactic Acid Fermentation from Fresh Cassava Roots in Tofu Liquid Waste by Streptococcus bovis
}

\author{
Suripto Dwi YUWONO and Takao KOKUGAN ${ }^{\dagger}$ \\ Department of Chemical Engineering, Tokyo University of Agriculture and Technology, \\ 2-24-16, Naka-machi, Koganei-shi, Tokyo 184-8588, Japan
}

\begin{abstract}
The effect of temperature on L-lactic acid fermentation from Fresh Cassava Root (FCR) by Streptococcus bovis was investigated in new mediums: tofu liquid waste (TLW), and TLW with $2 \mathrm{wt} \%$ concentrated maguro waste (TLW + CMW2) and also with standard medium (trypto soya broth; TSB), comparing with standard media (glucose in TSB). The experimental results showed that lactic acid fermentations from FCR in three mediums and glucose in TSB were optimum at $39^{\circ} \mathrm{C}$. The values of fermentation properties were found to be increasing in order FCR in TSB, glucose in TSB, FCR in TLW + CMW2, and FCR in TLW. The Arrhenius relationships for productivity and specific growth rate were then established. The values of activation energy $\left(E_{\mathrm{a}}\right)$ and deactivation energy $\left(E_{\mathrm{d}}\right)$ for lactic acid fermentation from all media were found to increase in order from FCR in TLW, FCR in TLW + CMW2, glucose in TSB, and FCR in TSB. The relations for activation energies and deactivation energies were in reverse to those for fermentation properties.
\end{abstract}

Key words: L-Lactic acid fermentation, fermentation temperature, Fresh Cassava Root (FCR), Tofu Liquid Waste (TLW), Streptococcus bovis.

\section{Introduction}

The cost of fermentation medium can account for nearly $30 \%$ of total lactic acid production cost [1]. Tejayadi and Cheryan [2]studied on lactic acid production from whey permeate and yeast extract, and reported that the costs of raw material processing account for $68 \%$ of the total cost [2]. To reduce the fermentation cost, tofu liquid waste (TLW) had been used in lactic acid fermentation from fresh cassava root (FCR) as a substitute for standard medium (trypto soya broth; TSB) [3]. However, the maximum productivity of lactic acid and specific growth rate were about $10 \%$ and $70 \%$ than those using TSB, respectively. To improve the productivity and specific growth rate for lactic acid fermentation, several nitrogen sources had been added to the media of FCR in TLW [4]. The maximum fermentation properties were obtained by supplementation of $2 \mathrm{wt} \%$ of concentrate maguro waste (CMW2) to the TLW medium. The fermentation properties were equivalent to those in the standard medium.

To operate the fermentation efficiently, know-ledge of kinetic characteristics of lactic acid production and specific growth rate are required. One of the important opera-

(Received 26 Aug. 2006: accepted 19 Jan. 2007)

Fax: +81-(0)42-388-7062, E-mail:kokugant@cc. tuat.ac.jp tion conditions is fermentation temperature. Temperature affects the fermentation performance of various bacteria for lactic acid production [5-8]. Narita et al. [5] produced lactic acid from corn starch by $S$. bovis and they obtained the highest productivity at $37^{\circ} \mathrm{C}$. However, none of these papers had discussed on activation energy. Tango and Ghaly [6] investigated the influences of temperature on the kinetics parameters of lactic acid fermentation by $L$. helventicus. However, the dependency of temperature on the maximum productivity and specific growth rate was not discussed. The present study was done to investigate the effect of temperature on the fermentation properties (maximum lactic acid concentration, $C_{\mathrm{La}}$; productivity, $P$; specific growth rate, $\mu$; and yield, $\eta$ ) for FCR in three mediums: TLW, TLW added to CMW of $2 \mathrm{wt} \%$ (TLW+ CMW2) and TSB by $S$. bovis. They were compared with those in standard media of glucose-TSB. The activation energy $\left(E_{\mathrm{a}}\right)$ and deactivation energy $\left(E_{\mathrm{d}}\right)$ were evaluated by Arrhenius plots for productivity and specific growth rate.

\section{Material and Methods}

S. bovis JCM 5802 (RIKEN, Saitama, Japan) was used in present work. It was grown at $37^{\circ} \mathrm{C}$ in MRS (Difco, USA) seed culture. The substrate of FCR was supplied from 

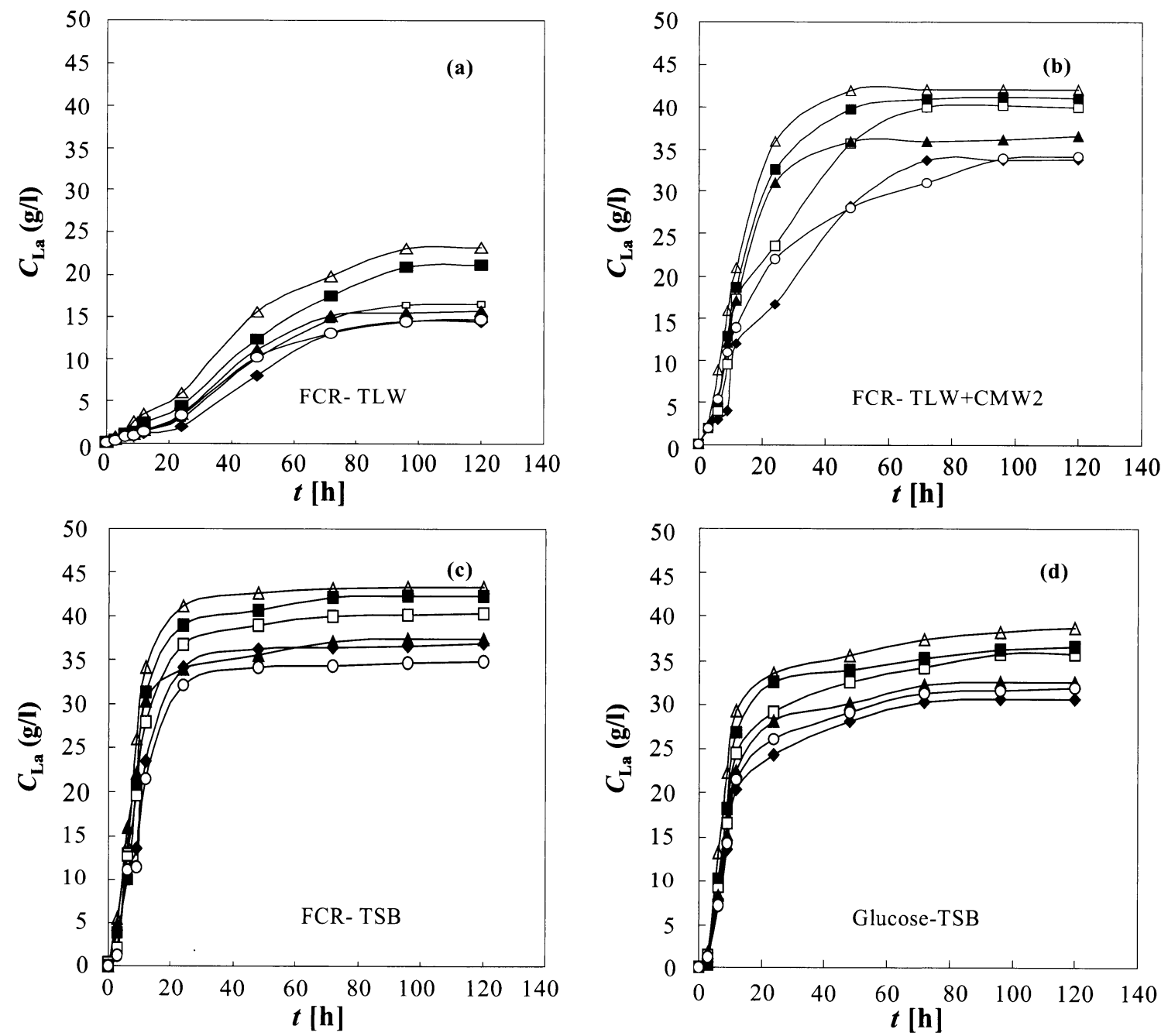

Fig. 1 Effect of temperature on L-lactic acid concentration at different controlled temperature in various media by $S$. bovis. Symbols: $32^{\circ} \mathrm{C}(\diamond), 35^{\circ} \mathrm{C}(\square), 37^{\circ} \mathrm{C}(\boldsymbol{\square}), 39^{\circ} \mathrm{C}(\triangle), 42^{\circ} \mathrm{C}(\boldsymbol{\Delta}), 45^{\circ} \mathrm{C}(\bigcirc)$. (a) FCR in TLW, (b) FCR in TLW+CMW2, (c) FCR in TSB and (d) Glucose in TSB.

Indonesia. The TLW was prepared from tofu manufacturing process as a medium. The CMW was supplied by Yaizu Suisan Kakou Co., Ltd (Shizuoka, Japan) as a nutrient supplement. TSB (Wako, Japan) was used as a standard medium. Batch fermentation for lactic acid production was carried out in $1 \mathrm{~L}$ bio-reactor (ABLE, Japan) with an initial sugar concentration of $50 \mathrm{~g} / \mathrm{L}$ and controlled at temperature from 32 to $45^{\circ} \mathrm{C}$ with $150 \mathrm{rpm}$. The culture $\mathrm{pH}$ was maintained at 5.5 by automatically addition of $6 \mathrm{~N}$ $\mathrm{NaOH}$ during batch fermentation. The lactic acid and glucose concentrations were analyzed by Biosensor (Oji Scientific Instruments Ltd., Himeji, Japan). Viable cells were counted by colony counting method in Colony Forming Unit.

\section{Results and Discussion}

From the analysis of fermentation broth by HPLC, $S$. bovis produced only L-lactic acid with $100 \%$ optical purity (data not shown). Figures 1 and 2 show the effect of temperature on L-lactic acid concentration and viable cell counts in various media, respectively. For the media of FCR-TLW the maximum L-lactic acid concentration was $23.2 \mathrm{~g} / \mathrm{L}$ (Fig. 1(a)). Furthermore, by addition of CMW of $2 \mathrm{wt} \%$ to media of FCR-TLW the maximum L-lactic acid concentration became $41.2 \mathrm{~g} / \mathrm{L}$ (Fig. 1(b)). These results were comparable with those in the media of FCR-TSB (Fig. 1(c)) and standard media (Fig. 1(d)). The L-lactic acid concentrations produced in FCR-TSB (Fig. 1(c)) were higher than those in standard media (Fig. 1(d)), because $S$. bovis has more extracellular $\alpha$-amylase activity to starch $[1,5]$.

The maximum viable cell count in media FCR-TLW was $6.5 \times 10^{7} \mathrm{CFU} / \mathrm{mL}$ (Fig. 2(a)). Viable cell count increased by the CMW addition in media FCR-TLW to $4.2 \times 10^{8}$ $\mathrm{CFU} / \mathrm{mL}$ (Fig. 2(b)). It was very close to the maximum of 

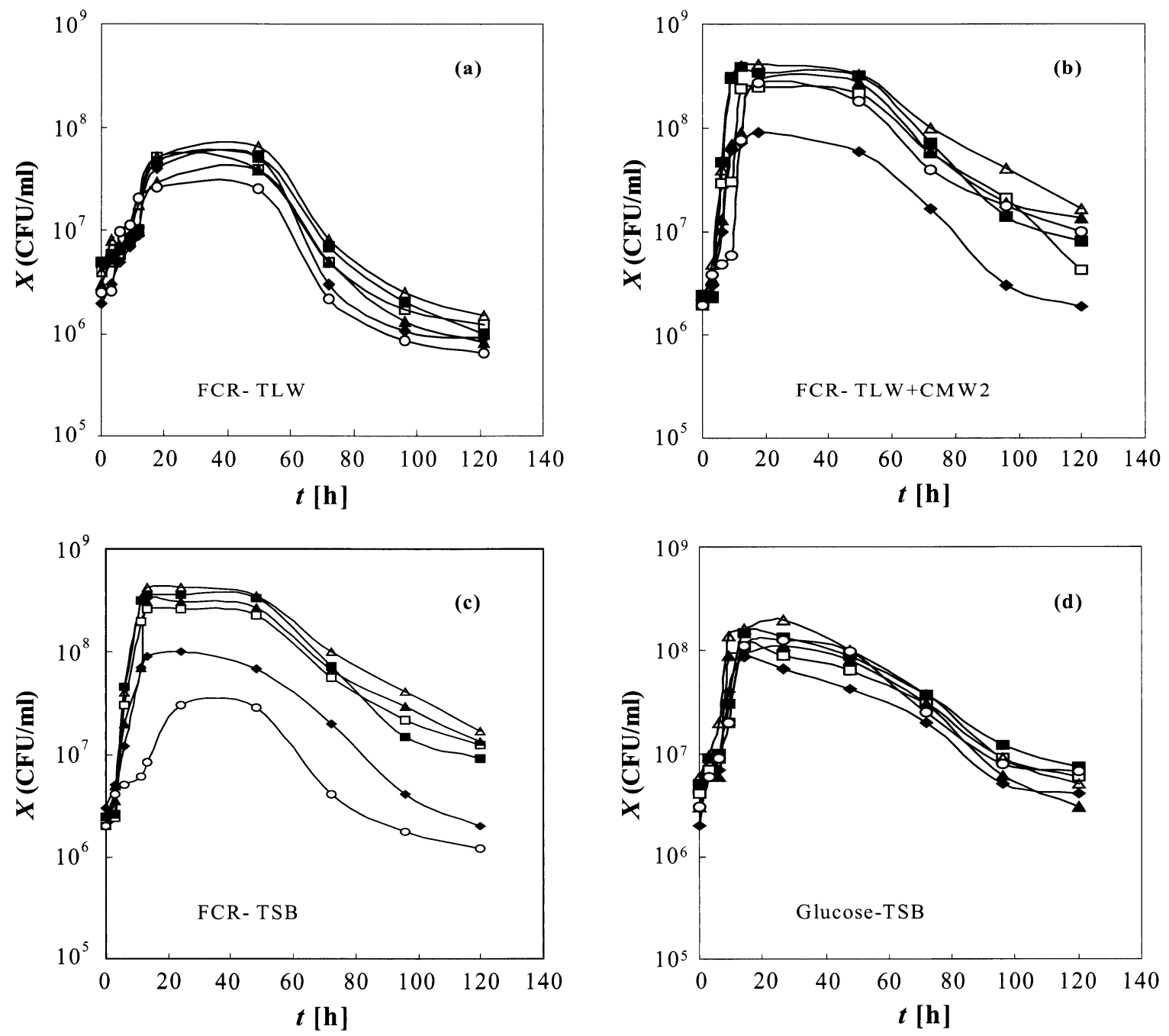

Fig. 2 Effect of temperature on viable cell count at different controlled temperature in various media by S. bovis. (a) FCR in TLW, (b) FCR in TLW+CMW2, (c) FCR in TSB and (d) Glucose in TSB. Symbols are same as shown in Fig. 1.

viable cell counts in the FCR-TSB (Fig. 2(c)) and standard medium (Fig. 2(d)). The L-lactic acid concentration behaved same as viable cell counts regard to temperature. They increase with increasing temperature, but decrease after optimum temperature for all media.

Figure 3 shows the Arrhenius plot for productivity (a) and specific growth rate (b). The productivity $(P)$ was obtained from maximum increasing rate of L-lactic acid concentration (Fig. 1) and the specific growth rate $(\mu)$ is calculated from the maximum slope of the relation between logarithmic viable cell count and fermentation time (Fig 2). The Arrhenius relationships for productivity and specific growth rate were then established. The fermentation properties productivity and specific growth rate increase with increasing temperature below $39^{\circ} \mathrm{C}$ and decrease with increasing temperature above $39^{\circ} \mathrm{C}$ for all media. The activation energy $\left(E_{\mathrm{a}}\right)$ and deactivation energy $\left(E_{\mathrm{d}}\right)$ were calculated for productivity and specific growth rate as follows.

For the ascending part (below $39^{\circ} \mathrm{C}$ ),

$$
\begin{aligned}
& \ln P=\ln A-\frac{E_{a}}{R} \frac{1}{T} \\
& \ln \mu=\ln A^{\prime}-\frac{E_{a}}{R} \frac{1}{T}
\end{aligned}
$$

and for the descending part (above $39^{\circ} \mathrm{C}$ )

$$
\begin{aligned}
& \ln P=\ln B-\frac{E_{d}}{R} \frac{1}{T} \\
& \ln \mu=\ln B^{\prime}-\frac{E_{d}}{R} \frac{1}{T}
\end{aligned}
$$

The ascending part is known as temperature activation, while the descending part is known as temperature inactivation. From Arrhenius plot the optimum temperature in new media for L-lactic acid fermentation by $S$. bovis was $39^{\circ} \mathrm{C}$, the same as standard media. Narita et al. [5] fermented L-lactic acid from raw corn starch in M17 broth at only three temperatures of $30,37,45^{\circ} \mathrm{C}$ using $S$. bovis 148 , 

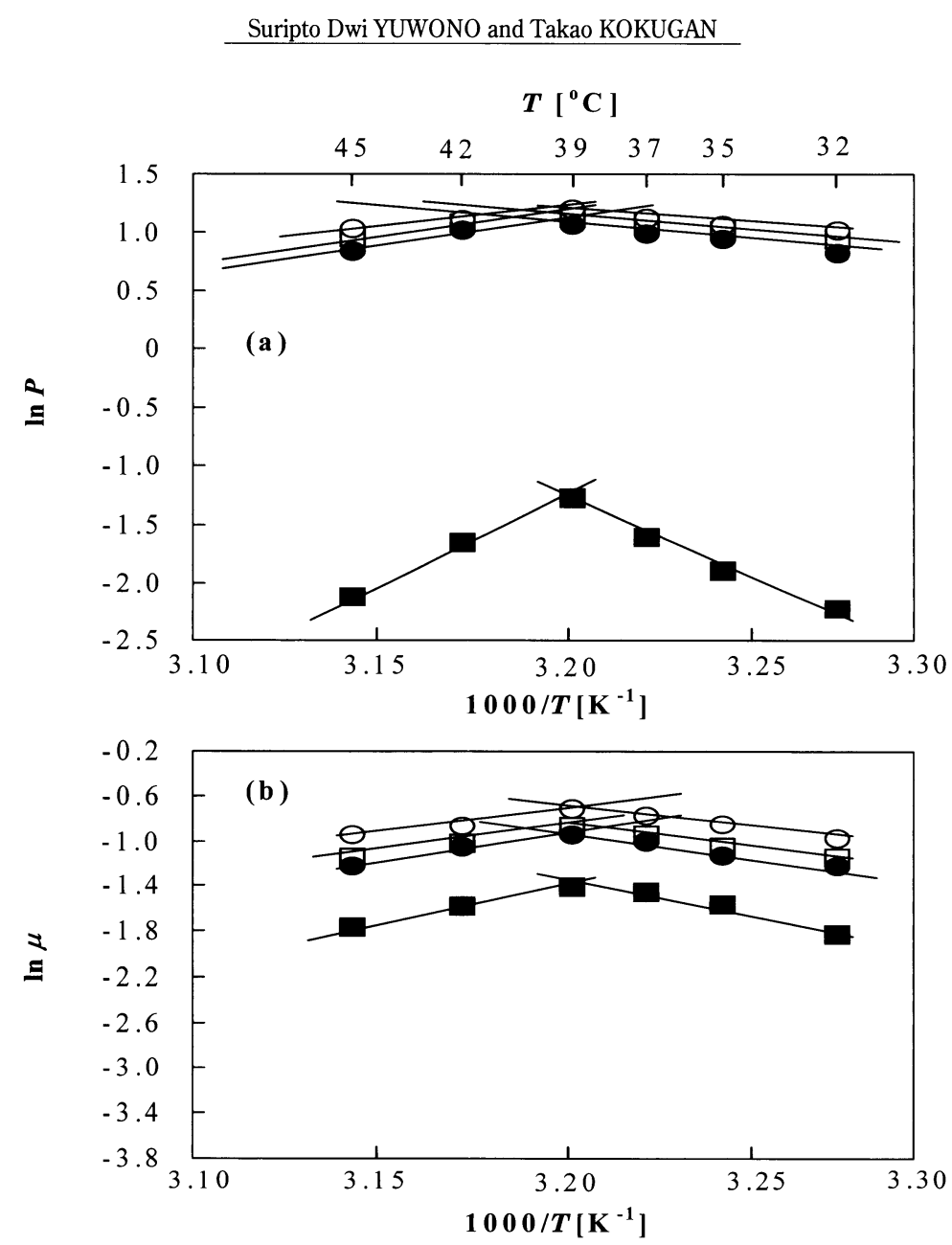

Fig. 3 Arrhenius plots for productivity (a) and specific growth rate (b). Symbols: FCR-TLW (ם), FCR-(TLW+CMW2) $(\square)$, FCR-TSB $(\bigcirc)$ and Glucose-TSB

and concluded the optimum temperature of $37^{\circ} \mathrm{C}$. However, Finlayson [9] studied L-lactic acid fermentation in standard medium by $S$. bovis $\mathrm{H} 13 / 1$ and obtained the yield of lactic acid of $1.80 \mathrm{~mol}$ product $/ \mathrm{mol}$ glucose at temperature of $39^{\circ} \mathrm{C}$ ( $\mathrm{pH} \mathrm{5.0)}$. However, both studies had not discussed the effect of temperature on activation energy $\left(E_{\mathrm{a}}\right)$ and deactivation energy $\left(E_{\mathrm{d}}\right)$.

Table 1 The activation energy $\left(E_{\mathrm{a}}\right)$ and deactivation energy $\left(E_{\mathrm{d}}\right)$ for productivity $(P)$ and specific growth rate $(\mu)$ in various media.

\begin{tabular}{lcccc}
\hline \multirow{2}{*}{\multicolumn{1}{c}{ Media }} & \multicolumn{2}{c}{$E_{\mathrm{a}}(\mathrm{kJ} / \mathrm{mol})$} & \multicolumn{2}{c}{$E_{\mathrm{d}}(\mathrm{kJ} / \mathrm{mol})$} \\
\cline { 2 - 5 } & $P$ & $\mu$ & $P$ & $\mu$ \\
\hline FCR-TLW & 99.9 & 48.5 & 129 & 49.6 \\
FCR-TLW+MWC2 & 25.6 & 32.7 & 29.6 & 39.0 \\
FCR-TSB & 19.2 & 29.3 & 21.2 & 31.4 \\
Glucose-TSB & 21.3 & 31.4 & 22.2 & 37.4 \\
\hline
\end{tabular}

The activation energy $\left(E_{\mathrm{a}}\right)$ and deactivation energy $\left(E_{\mathrm{d}}\right)$ from Arrhenius equation for productivity $(P)$ and specific growth rate $(\mu)$ in various media were given in Table 1 . The values of $E_{\mathrm{a}}$ and $E_{\mathrm{d}}$ for specific growth rate are higher than those for productivity in all media except in FCRTLW, respectively. In FCR-TLW, lactic acid concentration and the level of viable cells are lower than those in another mediums, because of less nutrients in TLW (Figs. 1 and 2). The carbon sources from substrate are needed for the growth of cells in a medium that lacked nutrients. Furthermore, in Arrhenius relation the transition-state potential for $P$ is higher than one for $\mu$. While in the rich nutrient media (FCR-TLW +CMW 2) the transition-state potential for $P$ is lower than one for $\mu$ and the product can be formed easily. However, the transition-state potential for $\mu$ in rich or less nutrient media doesn't have large divergence. Adamberg et al. [7] has reported that the $E_{\text {a }}$ from specific growth rate are larger than those for productivity from lactose by $S$. thermophilus. In all media, the deactivation energies were higher than the activation energies in all media. These results are consistent with enzyme denaturation by temperature which is much faster than enzyme activation [10].

At the optimum temperature of $39^{\circ} \mathrm{C}$ the fermentation properties of maximum L-lactic acid concentration $\left(C_{\mathrm{La}}\right)$, 
Table 2 Fermentation properties of L-lactic acid for $50 \mathrm{~g} / \mathrm{L}$ sugar concentration of substrate in various media at optimum temperature $\left(39^{\circ} \mathrm{C}\right)$ by $S$. bovis.

\begin{tabular}{lcccc}
\hline \multirow{2}{*}{ Fermentation properties } & \multicolumn{4}{c}{ Media } \\
\cline { 2 - 5 } & FCR-TLW & FCR-TLW+CMW2 & FCR-TSB & Glucose-TSB \\
\hline Maximum lactic acid, $C_{\mathrm{La}}(\mathrm{g} / \mathrm{L})$ & 23.2 & 41.1 & 43.3 & 38.6 \\
Productivity, $P$ (g/L.h) & 0.28 & 2.88 & 3.29 & 3.07 \\
Specific growth rate, $\mu\left(\mathrm{h}^{-1}\right)$ & 0.25 & 0.45 & 0.45 & 0.39 \\
Yield, $\eta(\%)$, & & & & \\
$\quad$ gross & 46.4 & 82.3 & 86.7 & 77.3 \\
$\quad$ net & 78.0 & 93.8 & 95.5 & 91.6 \\
\hline
\end{tabular}

productivity $(P)$, specific growth rate $(\mu)$ and yield $(\eta)$, for various media are summarized in Table 2 . The maximum lactic acid concentration and productivity for FCRTLW + CMW $2 \mathrm{wt} \%$ were about 1.7 times and 10 times higher than those for FCR-TLW, respectively. Furthermore, the specific growth rate for FCR-TLW+ CMW 2 wt \% was about 1.8 times for the FCR-TLW. The gross yield of lactic acid based on initial sugar concentration and the net yield of lactic acid based on concentration of sugar consumed were $77-86 \%$ and $91-95 \%$ expect in FCR-TLW, respectively. At optimum temperature the yield of lactic acid obtained was $95 \%$ in new media.

\section{Nomenclature}

$C_{\mathrm{La}} \quad$ : lactic acid concentration, $\mathrm{g} / \mathrm{L}$

$t \quad$ : fermentation time, h

$T \quad$ : temperature, ${ }^{\circ} \mathrm{C}, \mathrm{K}$

$P \quad$ : productivity, g/L.h

$\mu \quad$ : specific growth rate, $\mathrm{h}^{-1}$

$E_{\mathrm{a}} \quad$ : activation energy, $\mathrm{kJ} / \mathrm{mol}$

$E_{\mathrm{d}} \quad:$ deactivation energy, $\mathrm{kJ} / \mathrm{mol}$

$\mathrm{R} \quad$ : universal gas constant, $\mathrm{J} / \mathrm{mol} . \mathrm{K}$

$A, B$ : frequency factor, -

$\eta \quad$ : yield, \%

$X \quad$ : viable cell count, $\mathrm{CFU} / \mathrm{mL}$

\section{References}

[1] T. L. Miller, B. W. Churcill; Substrates for large-scale fermentation. In: A. L. Demain, L. A. Solomon, (Eds), "Manual of industrial microbiology and biotechnology", America
Society for Microbiology and Biotechnology. Wasinton, DC. 1986.

[2] S. Tejayadi, M. Cheryan; Lactic acid from cheese whey permeate. Productivity and economics of a continuous membrane bioreactor. Appl. Microbiol. and Biotechnol., 43, 242-248 (1995).

[3] A. Ghofar, S. Ogawa, T. Kokugan; Production of L-lactic acid from fresh cassava roots slurried with tofu liquid waste by $S$. bovis. J. Biosci. Bioeng., 100, 606-612 (2005).

[4] A. Ghofar, T. Kokugan; Effect of nutrient supplements from food manufacturing waste on L-lactic acid production by $S$. bovis using fresh cassava roots in tofu liquid waste. J. Chem. Eng. Japan, 39, 1132-1136 (2006).

[5] J. Narita, S. Nakahara, H. Fukuda, A. Kondo; Efficient production of L-lactic acid from raw starch by $S$. bovis 148. J. Biosci. Biol., 97, 423-425 (2004).

[6] M. S. A. Tango, A. E. Ghaly; Effect of temperature on lactic acid production from cheese whey using Lactobacillus helventicus under batch condition. Biomass and Bioenergy, 16, 61-78 (1999).

[7] K. Adamberg, S. Kask, T. M. Laht, T. Paalme; The effect of temperature and $\mathrm{pH}$ on the growth of lactic acid bacteria: a pH-auxostat study. Int. J. Food Micbiol., 85, 171-183 (2003).

[8] M. Hujen, Y. Linko; Effect of temperature and various nitrogen sources on L-lactic acid production by Lactobacillus casei. App. Microbiol. Biotechnol., 45, 307-313 (1996).

[9] H. J. Finlayson; The effect of $\mathrm{pH}$ on the growth and metabolism of Streptococcus bovis in continuous culture. J. App. Bact. 61, 201-208 (1986)

[10] M.L. Shuler, F. Kargi; "Bioprocess engineering, Basic Concepts”, 2nd Edition, Prentice Hall PTR, New Jersey, 2002, pp. 76-77. 